Illinois State University

ISU ReD: Research and eData

Theses and Dissertations

6-12-2017

\title{
Effects Of Mood On Processing In Event-Based Prospective Memory
}

Rachel A. Workman

Illinois State University, raworkman1@gmail.com

Follow this and additional works at: https://ir.library.illinoisstate.edu/etd

Part of the Cognitive Psychology Commons

\section{Recommended Citation}

Workman, Rachel A., "Effects Of Mood On Processing In Event-Based Prospective Memory" (2017). Theses and Dissertations. 783.

https://ir.library.illinoisstate.edu/etd/783

This Thesis is brought to you for free and open access by ISU ReD: Research and eData. It has been accepted for inclusion in Theses and Dissertations by an authorized administrator of ISU ReD: Research and eData. For more information, please contact ISUReD@ilstu.edu. 


\title{
EFFECTS OF MOOD ON PROCESSING IN EVENT-BASED PROSPECTIVE MEMORY
}

\author{
Rachel A. Workman
}

44 Pages

Different moods seem to elicit different processing styles (Hunt \& McDaniel, 1993, Storbeck \& Clore, 2005) and mood has been shown to affect retrospective memory in many ways. The current research investigated how induced mood affects event-based prospective memory (PM). The current study examined mood effects on focal and non-focal PM retrieval. Participants were induced into either a depressive or elated state using Velten statements directly prior to retrieval of the PM task. A main effect of task type was found, such that those in the focal condition completed the task quicker and more accurately than those in the non-focal condition. No effects of mood on PM cue detection accuracy or ongoing reaction times were significant. These results suggest that mood may not have a strong effect when induced at retrieval of the PM intention.

KEYWORDS: Affective States, Prospective Memory, Retrieval, Focality, Mood 


\section{EFFECTS OF MOOD ON PROCESSING IN EVENT-BASED PROSPECTIVE MEMORY}

RACHEL A. WORKMAN

A Thesis Submitted in Partial

Fulfillment of the Requirements

for the Degree of

MASTER OF SCIENCE

Department of Psychology

ILLINOIS STATE UNIVERSITY 
(C) 2017 Rachel A. Workman 


\title{
EFFECTS OF MOOD ON PROCESSING IN EVENT-BASED PROSPECTIVE MEMORY
}

\author{
RACHEL A. WORKMAN
}

COMMITTEE MEMBERS:

Dawn M. McBride, Chair

John C. Cutting 


\section{ACKNOWLEDGMENTS}

I would like to acknowledge the research assistants who helped collect data on this project, including Bailey Andrews, Amanda DeVore, and Margaret Shouse.

R. A. W. 


\section{CONTENTS}

Page

ACKNOWLEDGMENTS

CONTENTS

TABLES $\quad$ iv

FIGURES

CHAPTER I: INTRODUCTION 1

$\begin{array}{ll}\text { Prospective Memory } & 1\end{array}$

$\begin{array}{ll}\text { PM Views } & 3\end{array}$

Preparatory Attention View 3

Multiprocess View

Focal and Non-Focal Processing $\quad 7$

$\begin{array}{ll}\text { Mood and Memory } & 8\end{array}$

Mood and PM 9

$\begin{array}{ll}\text { The Current Study } & 14\end{array}$

$\begin{array}{ll}\text { CHAPTER II: METHODS } & 20\end{array}$

$\begin{array}{ll}\text { Participants } & 20\end{array}$

$\begin{array}{ll}\text { Materials and Design } & 20\end{array}$

$\begin{array}{ll}\text { Procedure } & 22\end{array}$

CHAPTER III: RESULTS 24

$\begin{array}{ll}\text { Mood Manipulation Check } & 24\end{array}$

$\begin{array}{ll}\text { PM Accuracy } & 25\end{array}$

PM Cue Reaction Times 26 
Correlational Analyses

PM Cue Monitoring

Reaction Times

Accuracy 


\section{TABLES}

Table

Page

1. Correlational Analysis for the Positive-Focal Condition 30

2. Correlational Analysis for the Positive-Non-Focal Condition 30

3. Correlational Analysis for the Negative-Non-Focal Condition 31 


\section{FIGURES}

Figure $\quad$ Page

1. Predicted PM Accuracy by Focality Factor and Mood 16

2. Predicted Ongoing Task RTs During Test Block 18

3. PM Accuracy by Focality Factor and Mood 26

4. Ongoing Task RTs During Test Block 28

5. Reaction Time Cost Patterns For Each Cue by Task Type 33 


\section{CHAPTER I: INTRODUCTION}

\section{Prospective Memory}

Prospective memory (PM) has been described as the ability to remember to perform an intended task in the future (Einstein \& McDaniel, 2005). Imagine a scenario in which a patient is making an appointment to see his or her doctor next week. The patient may receive a reminder card, or perhaps the patient would be willing to attempt to remember to go on his or her own. Regardless, if the patient remembers to attend their next appointment, he or she has successfully completed a PM task. In other words, the patient must fulfill the formed intention of attending the next appointment in order to successfully complete a PM task. Although this is just one example, these types of tasks are seen in many areas of daily life. PM is often compared to retrospective memory $(\mathrm{RM})$, or memories of past events. There are some very distinct differences between these two types of memory.

McDaniel and Einstein (2007) describe in their book, Prospective Memory: An Overview and Synthesis of an Emerging Field, several parameters that distinguish PM from RM. First, PM requires delayed execution of an intention. In RM tasks, often execution of memory is immediate or after a very short delay from the intention to retrieve a memory. For example, a RM task may involve recalling a list of words after seeing them or recalling details from a video that was just seen. Once the instruction to retrieve is given (or decided upon by the person), there is usually no delay before the person begins retrieval. In PM tasks, however, execution is not immediate after the intention to retrieve is formed. In other words, PM is memory for intended tasks in the future. For example, the intention to get milk from the grocery store on the way home from work can be an intention held for hours without completion. This delayed execution sets PM apart from RM. 
Another way in which PM and RM differ is that PM requires self-initiated recall. In RM lab studies, often times the intention to recall is prompted by something in the environment (such as a researcher's instruction to retrieve studied information). However, PM requires that the participant prompt retrieval on his or her own. This can often be difficult because not only do they have to remember to fulfill the intention, but they are also doing so within the context of other tasks.

Although researchers have been studying RM for a very long time, PM has just recently begun to attract attention in the field of cognitive psychology (McDaniel \& Einstein, 2007). Because of this, not all areas of PM have been explored. In fact, many areas of this field still have very limited knowledge of the ways in which PM differs from RM.

In the lab, PM is studied using different paradigms than traditional RM tasks. A typical RM study will consist of a study phase, a delay, then a test phase. In contrast, a PM lab study will consist of different phases: an ongoing task, a distraction, and then the ongoing task with a PM task added. Ongoing tasks are important in PM lab-based tasks because they simulate realworld experiences. In other words, people are often doing other things when the need to fulfill an intention arises. For example, someone could be cooking dinner when the time to take his medicine arises. In the lab, there are often two blocks of an ongoing task so that the researcher can compare performance on the two blocks: before and after the PM task is added. This comparison provides information to the researcher about how much of a cognitive load the participant may be experiencing from the PM task, which can be used as a presumed measure of monitoring for PM cues, when comparing the two blocks. Additionally, a simulation of realworld experiences is the main reason for a distractor task between the two ongoing task blocks. This distraction simulates a delay in responding that often occurs when completing PM tasks in 
everyday life. Although other elements can be added to increase the complexity of a PM task in the lab, this is the basic framework of most lab-based PM tasks.

There are two ways in which people may encode and complete PM intentions. First, PM tasks can be encoded based on time. A time-based PM task could be remembering to take medicine at a specific time (e.g., 10:00 PM) or within a window of time (e.g., taking medicine in 10 minutes). Second, PM tasks can be encoded based on the occurrence of an event. This event is something that prompts the person to complete the event. For example, if someone intended to buy some milk, passing the grocery store on the way home would be an event that may prompt him or her to stop in and purchase the milk. This would be considered event-based PM because this is an intention that must take place when a certain event occurs (i.e., when you get to the grocery store). Seeing the store may prompt the person to fulfill the intention, like getting some milk. In contrast, if the person took a different way home they may never notice the store, reducing the chance of fulfilling that intention.

\section{PM Views}

\section{Preparatory Attention View}

There are several different views surrounding PM and what processes are involved in successful completion of PM tasks. One of these views is the preparatory attentional and memory processes (PAM) theory. PAM theory was proposed by Smith (2003) and suggests that capacity-consuming preparatory processes are needed for successful completion of PM tasks. These preparatory processes refer to an effortful monitoring process of the environment for the PM cue. According to PAM theory, retrieval of any intention is not automatic because these processes must be occurring to successfully retrieve an intention. Therefore, embedding a PM task within an ongoing task (as described above) will reduce the cognitive resources available for 
the ongoing task. In turn, this will increase monitoring during the ongoing task, which will increase the cost to the ongoing task. This cost is traditionally measured in the lab by a comparison of ongoing task accuracy or speed for the first block of the ongoing task and the second block of the ongoing task in which the PM task has been added.

For these tasks, the researchers must compare the ongoing task blocks in order to investigate how long the trials in each block took for the participants as well as how accurately they completed the ongoing tasks. A comparison of accuracy and reaction times for the ongoing task blocks (with and without the PM task) allows the researcher to investigate the cognitive cost of the PM task. If a participant performs much worse or takes a lot more time on an ongoing task when a PM task is added, it can be assumed that the PM task required additional resources (McDaniel \& Einstein, 2007). This is seen in the data when it takes participants longer to complete the test block than the baseline block (Marsh, Hicks, \& Cook, 2006). Specifically, Marsh et al. (2006) provided support for this idea and also tested if perceived difficulty of the task would increase this discrepancy. The researchers found that when participants believed that the ongoing task would be difficult, they tended to allocate more cognitive resources toward it. In contrast, those who perceived the task to be easy allocated fewer resources toward the ongoing task (Marsh et al., 2006). Smith (2003) also conducted several experiments to test the PAM view. She tested whether reaction times were longer in a case where the PM task was embedded in the task, rather than a delayed PM condition. In the delayed PM condition, participants were told they did not have to remember to press the target key until after the lexical decision task was completed. The other condition was given standard PM instructions: to press a certain key when the PM cue was presented. It was found that participants were directing their capacities away from the ongoing task to focus on the PM task. In other words, participants in the regular PM 
condition had longer reaction times than those in the delayed PM condition. These results supported the PAM theory because they suggest that preparatory processes are engaged during the task in which participants are aware of an upcoming PM task.

\section{Multiprocess View}

The multiprocess (MP) view of PM retrieval was proposed by McDaniel and Einstein (2000) in response to the PAM view (Einstein \& McDaniel, 1990; Marsh et al., 2006). This view suggests that, depending on the type of PM task one is completing, different types of processing may influence prospective remembering. Past theory and data (e.g., Brewer, Knight, Marsh, \& Unsworth, 2010; Einstein et al., 2005) provide support for the idea that participants seem to rely on two types of processing to complete PM tasks: attentional monitoring and spontaneous retrieval (McDaniel \& Einstein, 2000).

Attentional monitoring is the process by which participants actively remind themselves to perform the PM task. This active monitoring requires an additional cost because presumably one is keeping track of multiple tasks at once such as monitoring for the PM cues and the ongoing task(s). This is the type of monitoring that researchers are able to measure with reaction times and accuracy of the ongoing task, as described in the PAM view. Spontaneous retrieval is a process that is similar to a "pop-out" reaction. Spontaneous retrieval may occur when a particularly salient cue is presented, a particularly strong connection between the cue and the PM task is encoded, or when people become aware of a discrepancy between a PM cue and a normal ongoing task trial (McDaniel \& Einstein, 2007). Simply, when a cue is presented, this can act as a reminder for the participant and the PM intention "pops" into in their mind. This allows participants to reduce their cognitive load from monitoring and just rely on cue recognition in order to complete the PM task. 
This view has been tested in several studies. In several experiments, Einstein et al. (2005) showed that a PM cost, in terms of longer ongoing task reaction times, was only present under certain conditions, even though PM accuracy was high in these conditions. For example, when the PM task was emphasized, cost was present, but when the ongoing task was emphasized, the cost was absent (Einstein et al., 2005).

Einstein et al. (2005) showed that there are times when PM performance is high, yet reaction times (a measure of cost) do not significantly increase with the addition of the PM task. In other words, there is no cost of the PM task with successful performance of the PM task. For example, in their fifth experiment, Einstein et al. (2005) compared reaction times for the ongoing task of a PM task block to an ongoing task with a RM task. They found that the participants performed similarly for a PM task and a RM task. This result provides support for the idea that the participants were not monitoring for PM cues when performing the PM task. Instead, the authors suggest that another process must be involved: spontaneous retrieval. Other studies have found similar results, suggesting that monitoring may not be the only processing strategy that participants are engaging in (Einstein \& McDaniel, 2005; Marsh, Hicks, Cook, Hansen, \& Pallos, 2003). To account for these results, McDaniel and Einstein (2000) suggest that a process known as spontaneous retrieval is relied upon to retrieve the PM task in response to the PM cues. According to the MP view, both processes are available for use in completing PM tasks. In other words, one process can be used as a backup for the other. Some research has provided evidence that, under different circumstances, one may rely on either of the two processes (Scullin, McDaniel, \& Shelton, 2013). For example, monitoring has been found to decrease if the ongoing task is emphasized as being important or if the ongoing task is particularly difficult. An 
additional factor that can explain when monitoring or spontaneous retrieval are used is focal processing of the PM cue features in the ongoing task.

\section{Focal and Non-Focal Processing}

Focal processing occurs when an ongoing task encourages the processing of the relevant aspects of the PM cue (Einstein \& McDaniel, 2005). For example, if the ongoing task is to count the number of vowels in a word, a focal PM task could be to note when there are two consecutive repeated vowels in a presented word (e.g., stool). This type of PM task is considered focal to the ongoing task, in that vowels are already being processed and the additional PM task should not add much cognitive load, because the cues can be noticed easily within the context of the ongoing task.

According to the MP view, spontaneous retrieval can aid PM task completion in the focal task case, because the PM cue (e.g., the word with the repeated vowels) can be noticed automatically as part of the vowel counting task. In contrast, a non-focal PM task for this ongoing task could be to indicate when a particular word appears. This adds an additional dimension to the task, in that, instead of just looking at the letters for each word, the entire word must be processed in order to notice the PM cues. Additional processing to the task is also present, which will increase cognitive load in order to successfully complete the PM task to respond when a particular word is shown. According to the MP view, participants given a focal task should rely more on spontaneous retrieval (Einstein \& McDaniel, 2005), because focal tasks

present a scenario in which a cue is more easily noticed as part of the ongoing task processing and therefore less monitoring is needed. However, non-focal tasks should increase this cognitive load, because monitoring is needed to notice the PM cues. Supporting this description of the PM tasks, Einstein et al. (2005) reported significant slowing of ongoing task completion in a non- 
focal PM condition when compared to a focal PM condition. Einstein et al. (2005) also found a difference between PM tasks that were focal to the ongoing task and those that were non-focal to the ongoing task. PM cost was present for non-focal tasks, but not for focal tasks. In addition, Brewer et al. (2010) compared focal and non-focal tasks completed by participants with a high or low working memory capacity. The authors found an interaction, such that there was no effect of working memory capacity for the focal task, yet participants with a high working memory capacity performed much better than those with low capacity on the non-focal task (Brewer et al., 2010). In short, the MP view suggests that non-focal tasks will rely more heavily on active monitoring than focal tasks, with spontaneous retrieval aiding PM retrieval in focal tasks.

\section{Mood and Memory}

Researchers have also investigated several individual difference factors that influence PM retrieval. For example, one's working memory abilities (Schnitzspahn, Stahl, Zeintl, Kaller \& Kliegel, 2013), impulsive tendencies (Cuttler, Relcov, \& Taylor, 2014), and age (e.g., Einstein, Holland, McDaniel, \& Guynn, 1992) have all been shown in past studies to be related to PM performance. Another individual difference that researchers have begun to investigate in PM tasks is mood. Mood has been found to influence both RM and PM tasks in past research (McBride \& Workman, in press). Generally, it has been found that encoding stimuli with positive or negative affect will encourage one of two encoding processes: relational processing or item-specific processing, respectively (Hunt \& McDaniel, 1993, Storbeck \& Clore, 2005). This idea is known as the mood as information hypothesis. Relational processing occurs when a person is focusing on the "big picture" or on the relationship between things in the environment. Item-specific processing occurs when a person focuses more on specific details of the environment. Negative affect has been shown to be closely related to item-specific processing, 
whereas positive affect has been shown to encourage relational processing (Fiedler, 2001; Gasper \& Clore, 2002). These phenomena have been investigated by researchers in several areas of memory research. For example, Storbeck and Clore $(2005,2011)$ investigated mood effects on false memory. They found that mood does, in fact, affect the creation of false memories through increased relational processing with a positive mood. Mood effects have also been found in more standard RM tasks where a congruent mood at study and test results in better memory for studied information (e.g., Eich, 1995). In addition to this support for relational processing, there has been support found in RM for item-specific processing. For example, Thorley, Dewhurst, Abel, and Knott (2016) conducted a study that was concerned with eyewitness testimony. They compared participants who were in a neutral mood to those who were induced into a negative mood to see how well they remembered certain facts about a non-emotional event. It was found that those in a negative mood were able to recall more details about the event than those in the neutral condition. This increase in performance suggests that the participants in the negative mood condition were engaged in an item-specific processing style. It is clear that mood encourages these types of processing in RM. However, it is yet unclear how mood affects PM task performance.

\section{Mood and PM}

To date, very little research has been conducted exploring how mood affects PM. It is important to know whether or not affective states affect PM in a similar way as RM, because some mood states may impair PM performance more than others and these tasks are important to successful completion of daily tasks. For example, will a person remember to take his or her medication if they are depressed? The current literature on this topic is still in its infancy. 
Because these two forms of memory are different in many ways, it is possible that mood may affect PM differently than RM.

To address this question, Kliegel et al. (2005) investigated the effects of a sad mood for a time-based PM task. Their participants either encountered a sad or neutral mood induction using film segments that primed the assigned mood. Their results showed that participants performed worse on a PM task after being induced into a sad mood (Kliegel et al., 2005) compared with the neutral mood. Following this study, Schnitzpahn et al. (2014) conducted an experiment investigating effects of positive mood. These researchers were also interested in the interaction of mood and age on time-based PM performance. Schnitzpahn et al. (2014) manipulated mood (positive, negative, or neutral control) in older and younger adults in a time-based PM task. They found that both positive and negative mood conditions hindered PM performance in younger, but not older, adults in comparison with the neutral mood condition. Both of these studies focused on time-based PM tasks and literature on time-based tasks is limited. However, to my knowledge, there have only been two studies that focused on the effects of mood state on event-based PM tasks: Knight, Brewer, Ball, DeWitt, and Marsh, (2015) and Rummel, Hepp, Klein, and Silberleitner (2012) - both are outlined here.

Knight et al. (2015) presented three experiments which showed some effects of mood on event-based PM. The first experiment investigated mood at encoding (positive, negative, or control). Participants were given a positive mood induction, a negative mood induction or no mood induction (depending on the assigned condition), and then they encoded the PM intention. The participants were out of the induced mood before PM retrieval (measured by a mood manipulation check) so the effect of mood was on encoding of the PM task only. The results showed that a negative mood hindered PM accuracy, but the positive mood condition scores 
were not significantly higher than the control condition scores. In the second experiment, they introduced the factor of cue valence. Because mood-congruent effects have been reported in studies with RM tasks (e.g., Eich \& Metcalfe, 1989), the researchers chose to include PM cues with a negative valence to see if a match between the negative mood condition and a negative cue valence influenced PM performance. In this experiment, the methods were the same as in the first experiment except for the change in cue valence. Interestingly, the valence of the cue hindered those in the negative mood condition further when the cue had a negative valence (as compared with scores for those in the negative mood condition with PM cues of neutral valence). The negative valence of the cue also hindered the performance of the positive mood condition, such that the positive and negative mood conditions were not significantly different from each other with negative PM cues. Thus, both of the mood conditions were significantly worse than the control condition, such that those in either the positive or negative mood conditions performed less accurately on the PM task than those in the control mood when a negative cue was used. The third experiment in this study included re-induction of the encoding mood (positive, negative, or no mood induction control) at recall. Only negative-valence cues were used in this experiment. Interestingly, those in the positive and negative mood conditions performed significantly better than participants in the previous experiment with negative cues, and just as well as the control condition. To summarize, Knight et al. (2015) found that mood does, in fact, affect event-based PM performance. Specifically, they found that many different facets of mood, including cue valence and a reinstatement of the same mood from encoding just before recall, influence how PM performance is affected.

Knight et al. (2015) did find that mood affects PM, but it is still not entirely clear how each factor (i.e., cue valence, when the mood is induced) plays a role in PM retrieval. Also, there 
is an interesting component to point out about this study: All three of their experiments included focal tasks. For the focal task, the researchers asked participants to remember specific words and indicate when they saw them during a lexical decision task. This is important to note because, as outlined earlier, focal and non-focal tasks can rely on different retrieval processes in PM tasks. In addition, positive and negative moods encourage reliance on relational and item-specific processing (Rummel et al., 2012), respectively, as described above. This is important for PM tasks, as a relational or item-specific processing style may influence the way in which a focal or non-focal task is processed.

In contrast to Knight et al. (2015), Rummel et al. (2012) focused their study more on investigating the types of processing involved in PM retrieval while in different mood states. These researchers tested the mood as information hypothesis (which they termed the affectiveregulation-of-processing model). Recall that this model suggests that people tend to maintain a global, or relational, processing style when in a positive mood, and a local, or item-specific, processing style when in a negative mood. In their experiment, Rummel et al. (2012) had participants partake in a positive, neutral, or negative mood induction with film clips directly before encoding the PM instructions, and then asked them to perform a non-focal PM task embedded in a lexical decision task. They found support for an effect of mood on PM, such that the performance in the sad (negative) mood condition was significantly higher than that in the happy condition. This result conflicts with the result reported by Knight et al. in their first experiment, but supports a difference in processing style based on mood, because this is what is expected for a negative mood in a non-focal task. If a negative mood is induced, it is thought that participants will employ an item-specific processing style. In a non-focal task, this processing style may be more helpful than a relational processing style because it is more likely that a 
person will process each item individually, which can aid monitoring (the process the MP view suggests will be needed for non-focal tasks). This individualistic processing may allow for more efficient monitoring. However, a relational processing style might encourage a person to gloss over the specific words in attempts to relate them to the ongoing task instead of recognizing them as PM cues, which should be less helpful in a non-focal PM task. However, the conclusions made by Rummel et al. (2015) rely heavily on the assumption of monitoring for the non-focal task. Monitoring allows participants to process the items as possible cues, making it more likely that they will notice cues if they are using item-specific processing. However, because this experiment did not include an initial measure of the ongoing task, there was no measure of PM cost (a measure of monitoring) reported in this study. Because a comparison between two ongoing blocks cannot be made in this case, the assumption of monitoring in the task was not tested. Therefore, the presence of monitoring in their non-focal PM task was unclear. Although these studies give the field insight as to how mood might affect PM tasks, it is important to continue to explore this topic in order to fully understand the ways in which mood affects PM. Not only is the current literature on mood and PM in its infancy, but some limitations of previous studies increase the difficulty of making solid conclusions. For example, Knight et al. (2015) studied focal PM, whereas Rummel et al. (2012) studied non-focal PM. According to the MP view, monitoring is more important for non-focal than focal PM task completion. However, Rummel et al. did not present a measure of monitoring in their study. Thus, it is unclear how mood effects might differ across different types of PM tasks that rely on different processing strategies for completion. In order to make more solid conclusions about how positive and negative moods affect PM retrieval, more research is needed. 


\section{The Current Study}

The current study aimed to examine how mood affects the processing of focal and nonfocal PM tasks in one study. Mood was manipulated (positive and negative) in order to determine effects on the PM task type (non-focal, focal, and no PM). Mood was induced directly before the second block of ongoing task trials. The current study tested this hypothesis that could account for the discrepancy between the results for Knight et al. (2015) and Rummel et al. (2012). A comparison of focal and non-focal tasks was conducted to see how focality influences PM accuracy and the degree to which participants rely on monitoring in the PM task under different mood conditions. Monitoring was measured by investigating reaction time and accuracy differences between the baseline and PM blocks of ongoing trials. These reaction times and accuracy were compared across PM task and mood conditions to investigate how focality and processing style interact to affect PM cost. In addition, by including an initial ongoing task block, a measure of PM cost can be made in order to examine the presence of monitoring in the different conditions.

As mentioned, Rummel et al. (2012) provided some insight into this effect with their study by employing a non-focal task. However, as described, the conclusions made were limited because of the methodology used. Namely, the researchers excluded an initial ongoing task block absent of a PM task. The inclusion of a baseline block of ongoing task trials allows researchers to measure the degree to which participants monitor for PM cues during the PM block of ongoing task trials. In addition, according to the MP view, the focality of the PM task affects these processes. Rummel et al. (2012) employed a non-focal task, whereas Knight et al. (2015) used a focal task. This may be why a positive mood decreased overall PM performance in Rummel et al.'s (2012) study, but saw no effect on performance in Knight et al.'s (2015) study in the 
positive mood condition. See Figure 1 below for a graph of the expected PM accuracy results in the current study. The positive mood may increase performance in the focal task because this may encourage a relational processing style. For a focal task, a relational processing style may be beneficial because it will aid spontaneous retrieval of the PM task when one encounters a PM cue. Utilizing a cue that requires a processing style that is close to the processing style needed for the ongoing task (i.e., a focal task) may allow reliance on spontaneous retrieval of PM cues because the cue is more likely to "pop out" when employing a relational processing style. However, this increase in performance should not be seen for positive moods in a non-focal task, like in Rummel et al.'s (2012) study, because the cue is not likely to be processed easily when there is little overlap between the PM cue and the ongoing task to be detected with relational processing. For a negative mood, however, both studies showed a decrease in performance for the negative mood condition. It is thought that a negative mood elicits an item-specific processing style. This, for a focal task, may not be very beneficial. This is because a focal task is completed more accurately and with less cost when there is a reliance on spontaneous retrieval. However, if an item-specific processing style is being used, this cost may decrease accuracy in this type of task. For a non-focal task, this item-specific processing style may be more beneficial than in a focal task. This is because a non-focal task requires more monitoring than a focal task. However, this benefit may be minimal because of the cost associated with an item-specific processing style. 


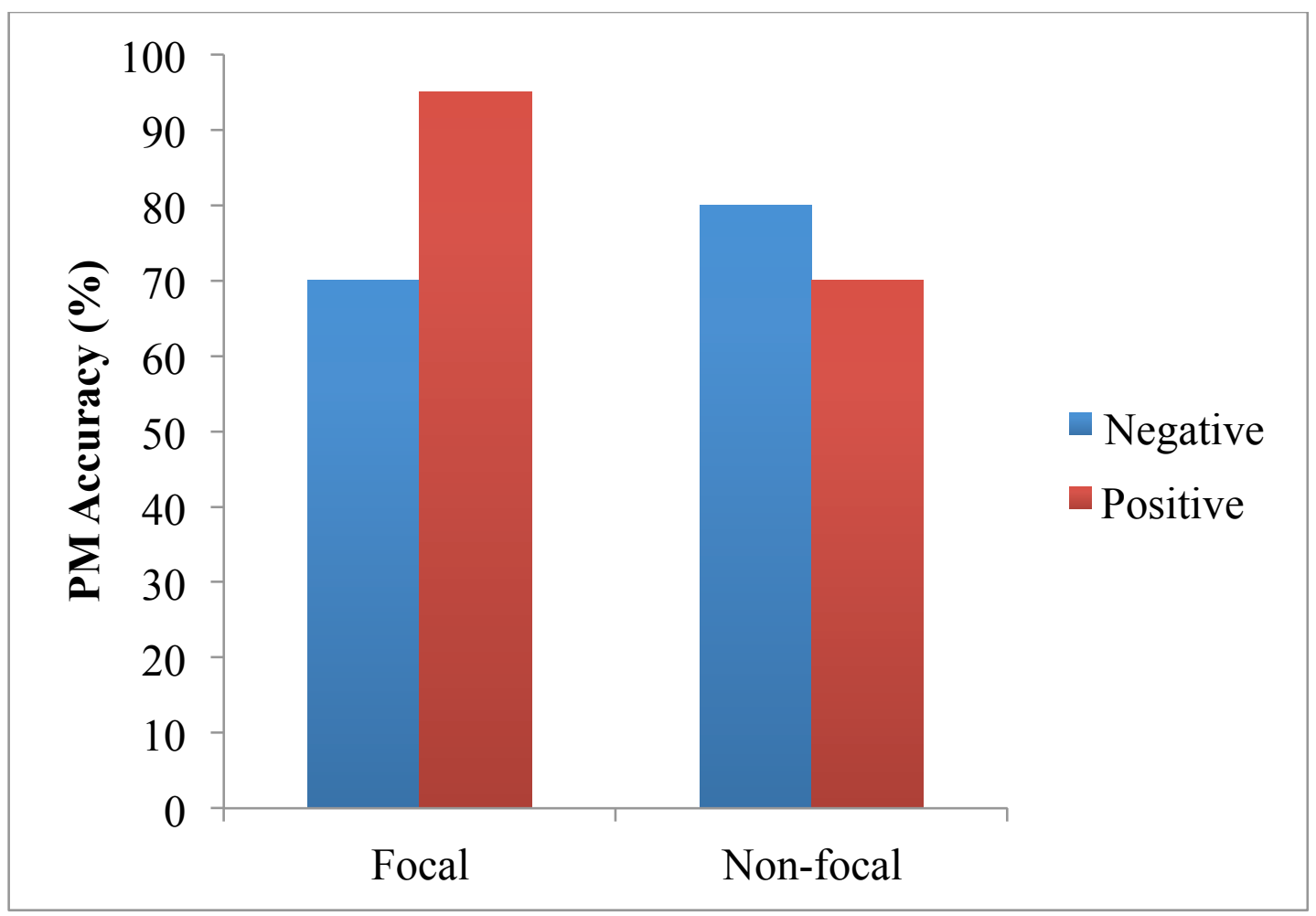

Figure 1. Predicted PM accuracy by focality factor and mood. The above figure shows the predicted PM accuracy outcomes for each condition. PM accuracy is expected to be the highest in a positive-focal condition because a positive mood elicits a relational processing style, which may be beneficial in a focal condition. An effect is also expected for the non-focal task type, such that a negative mood may be more beneficial than a positive mood. This is because a negative mood elicits an item-specific processing style, which may be more beneficial in a nonfocal task than a relational processing style.

It is also expected that certain patterns in reaction times may emerge. For example, an overall main effect of task type may emerge such that a focal task will be completed more quickly than a non-focal task. This is because of a reliance on spontaneous retrieval for this type of task. In addition, a main effect of mood is hypothesized, such that participants in the negative 
mood condition will complete the task more slowly than those in the positive mood condition. This is hypothesized because a negative mood is thought to elicit an item-specific processing style, which may induce longer reaction times. An item-specific processing style may encourage each trial to be examined more closely and in more detail, which may result in higher reaction times. See Figure 2 below for a graph of the expected results for ongoing task reaction times in the current study. 


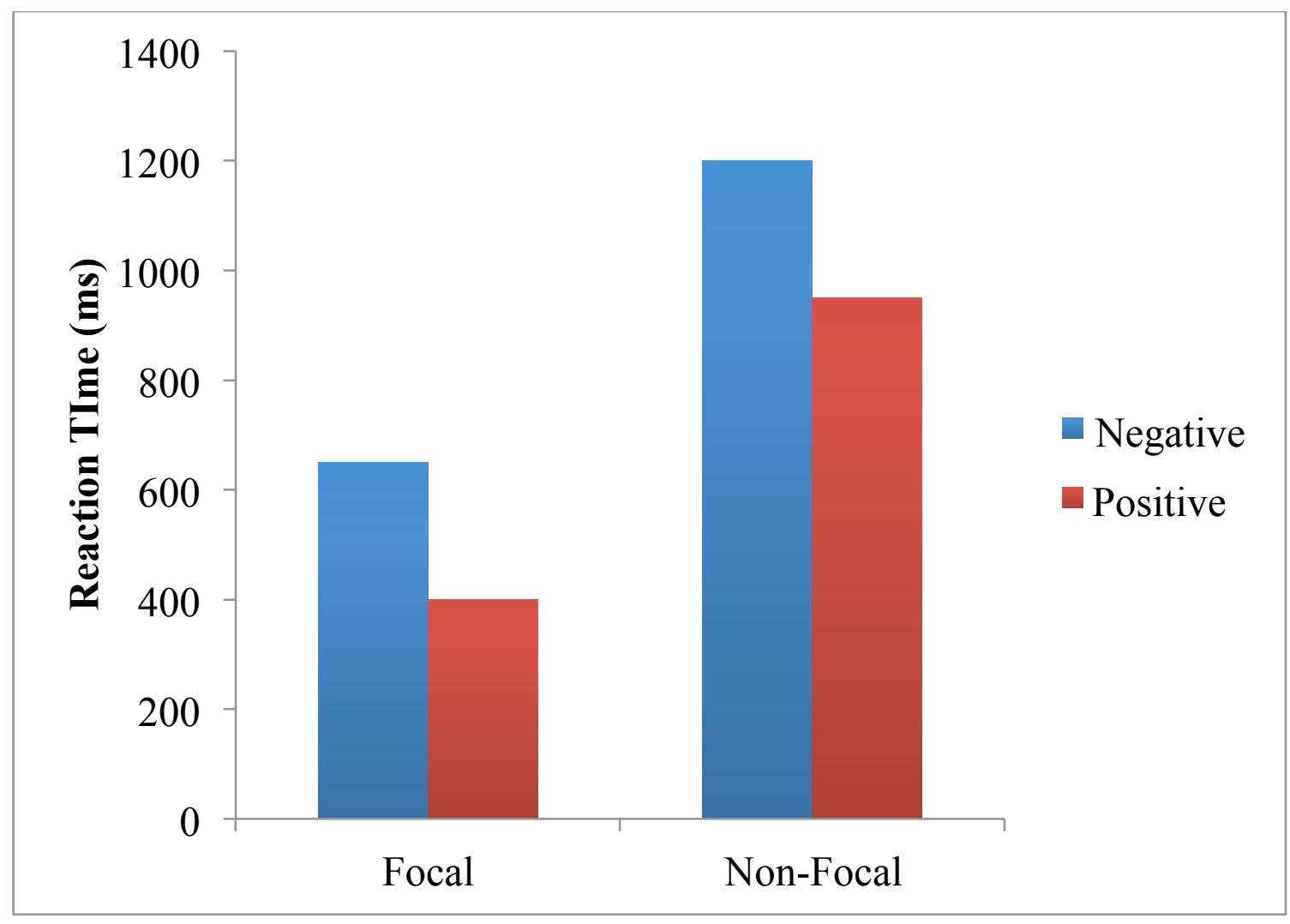

Figure 2. Predicted ongoing task RTs during test block. It is expected that a negative mood will show longer reaction times than a positive mood. This is because a negative mood elicits an item-specific processing style, which may elicit more monitoring than a relational processing style. It is also expected that a focal task will show shorter reaction times than a non-focal task. A focal task may allow for a larger reliance on spontaneous retrieval, which would lower ongoing task cost.

Hypotheses for the current study come from the expected processing styles primed by different mood states, as described by the mood-as-information hypothesis. It is expected that in the focal condition, those in the positive mood condition should perform better on the PM task than those in the negative mood condition. In short, a positive mood should encourage a 
relational processing style, which may aid spontaneous retrieval for focal tasks where the overlap between the PM cues and ongoing task is high. A relational/global processing style will allow for a focus on the relationship between different elements in the tasks. In the focal condition, this focus on the relationship between the items should aid spontaneous retrieval. However, in the non-focal condition, a negative mood should be more useful in retrieving PM cues. This is because a negative mood encourages item-specific processing, which should aid in the monitoring process in the non-focal condition, where monitoring is more likely in this task than in the focal task. In this case, a negative mood may support the recognition of a PM cue because each item is processed individually, in which case the cue may be more easily recognized as participants monitor for those cues. 


\section{CHAPTER II: METHODS \\ Participants}

One hundred ninety-five students were recruited from the Psychology Department subject pool at Illinois State University and given class credit or extra credit for participation. There were 6 total between-subjects conditions, each with 29-32 participants. A preliminary power analysis was conducted using $\mathrm{G}^{*}$ Power software (Faul, Erdfelder, Lang, \& Buchner, 2007) to determine the sample size. First, a need for 155 participants was determined using the following criteria: $\alpha=.05$, Power $=.80$, and a medium effect size (Cohen's $f=.25)$. In an effort to be more conservative, a total sample size of 180 participants was the target. However, because of a need to delete certain participants, a total sample of 195 was collected. A total of 14 participants were deleted from analysis for misunderstanding the instructions $(n=1)$, asking about the PM cue directly before the PM block $(n=11)$, forgetting the task all together $(n=1)$, or suspicion of being under the influence $(n=1)$. A sample size of 181 was then remaining for analyses.

\section{Materials and Design}

The experimental programs were presented on a Macintosh computer with SuperLab 5.0 software. The current study has a 3 (PM task type: focal, non-focal, no PM control) $\times 2$ (Induced mood at retrieval: positive, negative) between-subjects design. The ongoing task in this study was a lexical decision task (LDT). In this task, participants were shown a letter string and asked to determine whether or not the string of letters is a word. For the LDT blocks, 180 words were chosen from the English Lexicon Project (ELP, Balota et al., 2007). These words were controlled for the number of syllables the words contained ( 2 syllables in all words), total length of the word (5-7 letters), and reaction times in a LDT conducted for the ELP (500-600 ms). Each word was scrambled into a pronounceable non-word and the scrambled letter versions were used for 
non-word trials in the other block of the study for which the words were used. For each block of LDT trials, 90 words and 90 non-words were presented. In the PM block, an additional 3 words were shown as PM cues for a total of 183 trials. A word and its non-word counterpart were not shown in the same LDT block.

The PM cues (rabbit, lion, kitten) were chosen from the Affective Norms for English Words database (ANEW; Bradley \& Lang, 1999) and were controlled for valence and arousal. Words in the ANEW database are rated on their valence and arousal separately. These ratings range on a scale of 1 to 9 for each characteristic. Ratings below 4 are considered low, or negative for valence. Ratings above 6 are considered high, or positive. Any ratings between 4 and 6 for each characteristic are considered moderate or neutral. Each of the words chosen for the current experiment are neutral or slightly positively toned in valence $(M=6.33, S D=0.67$, range $=5.57$ 6.86) and are moderately arousing $(M=5.10, S D=1.09$, range $=4.02-6.2)$.

In this study, mood was manipulated using the Velten (1967) statements. This is a method of manipulating mood in which the participant is presented with statements on the screen and asked to vividly imagine himself or herself in each situation described by the statement. These statements are designed to become gradually more negative (depressive) or positive (elated) in order to ease participants into the target mood. Mood manipulation checks were also given to ensure the induction worked using the Brief Mood Introspection Scale (BMIS; Mayer \& Gasschke, 1998). In the BMIS, participants are presented with adjectives (e.g., sad, angry, happy) and asked to rate how much their mood matches the adjective on a 1 to 7 scale with a final question asking them to rate their overall mood on a 1 to 10 scale. 


\section{Procedure}

Participants entered the lab and then began the consent process. Any participant who had current psychological issues, particularly mood disorders, was excused from the study without loss of credit. After providing an understanding of all risks, participants were asked for their written consent to continue. Participants were then asked to complete the BMIS to obtain their baseline mood. Then participants were asked to complete one block of the LDT to assess their baseline rate of response. For this task, participants were asked to press the "A" key for every word and the "L" key for non-words. They were told to complete the task as quickly as possible, but not at a cost to accuracy. Each LDT block in the current experiment included 180 trials (plus the three PM cues in the second block), with an equal proportion of words and non-words. Participants were given practice trials before beginning the first LDT block to ensure they understand the task and to reduce practice effects.

The participants were then given PM instructions according to their assigned condition. Participants in the focal and non-focal PM conditions were instructed to respond to the PM cues by pressing the " $t$ " key. PM cues for every participant occurred on trials 50, 109, and 172. For the focal condition, participants were asked to respond to the specific PM cues: rabbit, lion, and kitten. After the presentation of the PM cues, participants were asked to recall the 3 cues to ensure that they had encoded them well. In the non-focal condition, participants were asked to respond to words that belong to the animal category. In the no PM control condition, participants were not given a PM task. A 3 min distractor task (Sudoku puzzle) was given after these instructions. A mood induction via Velten statements then occurred. Each statement was presented for $15 \mathrm{~s}$. The participants were asked to read each statement and to imagine themselves in the situation described by the statement for the amount of time that the statement appears on 
the screen. After completing the BMIS again, participants were then asked to complete a second LDT block that contains the PM cues. If the participant asked about the PM cue before or during this LDT block ( $\mathrm{n}=11$, see Participants section), they were replaced in the experiment. Following the second LDT block, participants completed a final BMIS to ensure that the target mood lasted throughout the LDT block. At the end of the experiment, participants were induced into a positive mood so that they left the lab in a positive mood. After participating, the participants were debriefed thoroughly. In addition, participants received a hard copy of the debriefing script in case any questions or issues arose with the study and methodology. 


\section{CHAPTER III: RESULTS}

Participants who scored lower than $90 \%$ on the LDT were eliminated from the analyses to ensure participants were paying enough attention to the LDT task $(n=2)$. Thus, 179 data sets were available for analysis. LDT data were also trimmed by removing any trials with RTs below 200 ms or above 3 standard deviations from the participant's mean in order to remove outliers $(0.69 \%$ of trials $)$. Accuracy and reaction time data were analyzed from the LDT trials. ANOVAs and ANCOVAs were conducted in the current study, with an alpha level set at $a=.05$. All posthoc pairwise comparisons are reported with Bonferroni adjustments.

\section{Mood Manipulation Check}

An independent-samples t-test was conducted to determine if any differences in mood were found between groups before any manipulations occurred. This analyses showed that the difference between those in the positive mood condition $(M=4.89, S D=.81)$ and the negative mood condition $(M=5.02, S D=.90)$ at the beginning of the study was not significant, $t(179)=-$ $1.01, p=.31$. For each mood condition, a paired-samples $t$-test was conducted to determine if a difference occurred between the baseline BMIS and the BMIS collected after the mood induction. For the positive mood, the average mood before a mood induction $(M=4.89, S D=$ .81) was significantly lower than after the mood induction $(M=5.09, S D=.87), t(89)=-3.60, p$ $=.001$. For a negative mood, the average mood before a mood induction $(M=5.02, S D=.90)$ was significantly higher than after the mood induction $(M=4.57, S D=.99), t(90)=4.62, p<$ .001 .

An additional paired-samples $t$-test analysis was conducted to determine if moods returned to baseline by the end of the PM LDT Block. When a negative mood was induced, the mood after induction $(M=4.57, S D=.99)$ was significantly stronger (lower) than the mood after 
the final LDT block $(M=4.75, S D=.93), t(90)=-4.39, p<.001$. When a positive mood was induced, the mood after induction $(M=5.09, S D=.87)$ was significantly stronger (higher) than the mood after the final LDT block $(M=4.99, S D=.89), t(89)=1.99, p=.049$.

\section{PM Accuracy}

An ANOVA was conducted to explore the effects of mood and task type on PM accuracy with a 2 (PM task type: focal, non-focal) X 2 (Mood induction: positive or negative) design. A main effect of task type was found, showing that overall the focal task $(M=.64, S D=.39)$ condition was significantly more accurate than a non-focal task $(M=.46, S D=.32), F(1,118)=$ $7.22, p=.008$. Neither the main effect of mood induction nor the interaction was significant ( $p$ 's $>$.05). See Figure 3 for the PM accuracy means by condition. 


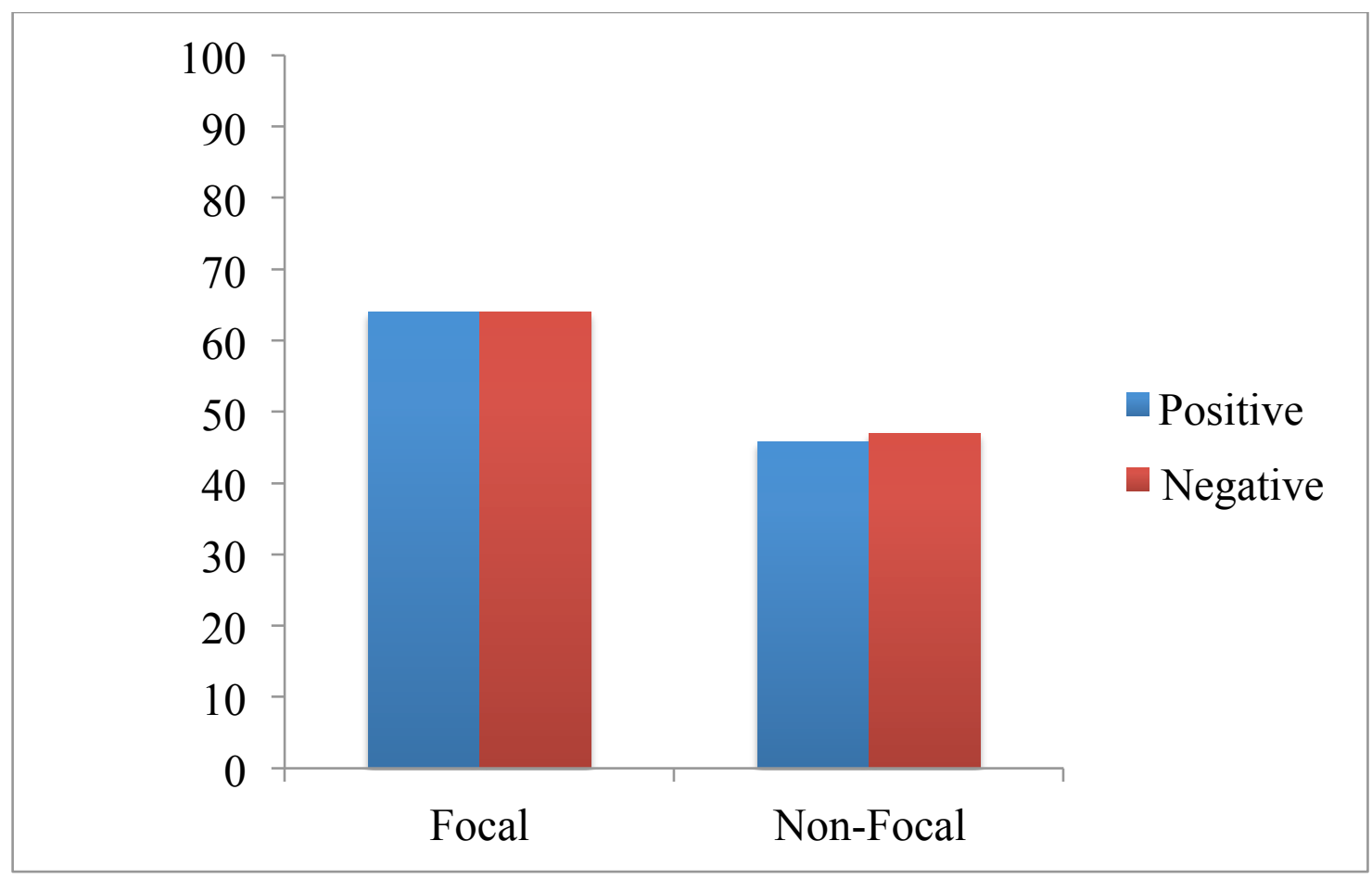

Figure 3. PM accuracy by focality factor and mood. A focal task advantage was found. No other effects were found.

\section{PM Cue Reaction Times}

An ANOVA using the same 2 X 2 design was conducted for PM cue trial reaction times. This analysis yielded a significant effect for task type, such that a focal task $(M=1399.43 \mathrm{~ms}$, $S D=761.43 \mathrm{~ms})$ was completed significantly more slowly than a non-focal task $(M=1066.97$ $\mathrm{ms}, S D=419.56 \mathrm{~ms}), F(1,118)=8.86, p=.004$. This effect may have been due to the extra time needed to spontaneously retrieve the PM task when a PM cue was encountered in the focal task condition. Neither the main effect of mood induction nor the interaction was significant $(p>.05)$. 


\section{Ongoing Task Accuracy}

An ANCOVA was used to analyze ongoing task accuracy with a 2 (Mood: Positive, Negative) X 3 (Task Type: focal, non-focal, no PM task control) design with baseline LDT accuracy scores used as a covariate. No main effects or interactions were found for this analysis, all $p$ 's $>.19$. When the no PM control group was omitted from the analysis to compare the PM task types, no significant effect was found, $F(1,117)=2.46, p=.12$. When investigating the no PM control group separately, no effect of mood was found, $F(1,55)=.02, p=.90$.

\section{Ongoing Task Reaction Times}

An ANCOVA was also used to analyze ongoing task reaction time data with a 2 (Mood: Positive, Negative) X 3 (Task Type: focal, non-focal, no PM task control) design with baseline block RTs used as a covariate. A main effect of task type was found, showing faster reaction times for the no PM control $(M=651.14 \mathrm{~ms}, S D=111.78 \mathrm{~ms})$ than the focal $(M=739.28 \mathrm{~ms}$, $S D=99.87 \mathrm{~ms})$ and non-focal $(M=742.96 \mathrm{~ms}, S D=137.06 \mathrm{~ms})$ conditions, $F(2,174)=21.40$, $p<.001$. This result indicates a cost to the ongoing task in speed due to the PM task in both of the PM task conditions. There was no significant main effect of mood, $F(1,174)=.84, p=.36$, or an interaction for this analysis, $F(2,174)=.65, p=.51$. See Figure 4 for mean ongoing task reaction times by condition. In addition, when analyzing only the conditions with a PM task, no effect was found for mood, $F(1,117)=.008, p=.93$, task type, $F(1,117)=.06, p=.81$, or the interaction, $F(1,117)=.84, p=.36$. When analyzing only the no PM task control condition separately, no effect of mood was found, $F(1,56)=1.12, p=.29$. See Figure 4 for a summary of ongoing task reaction times by condition. 


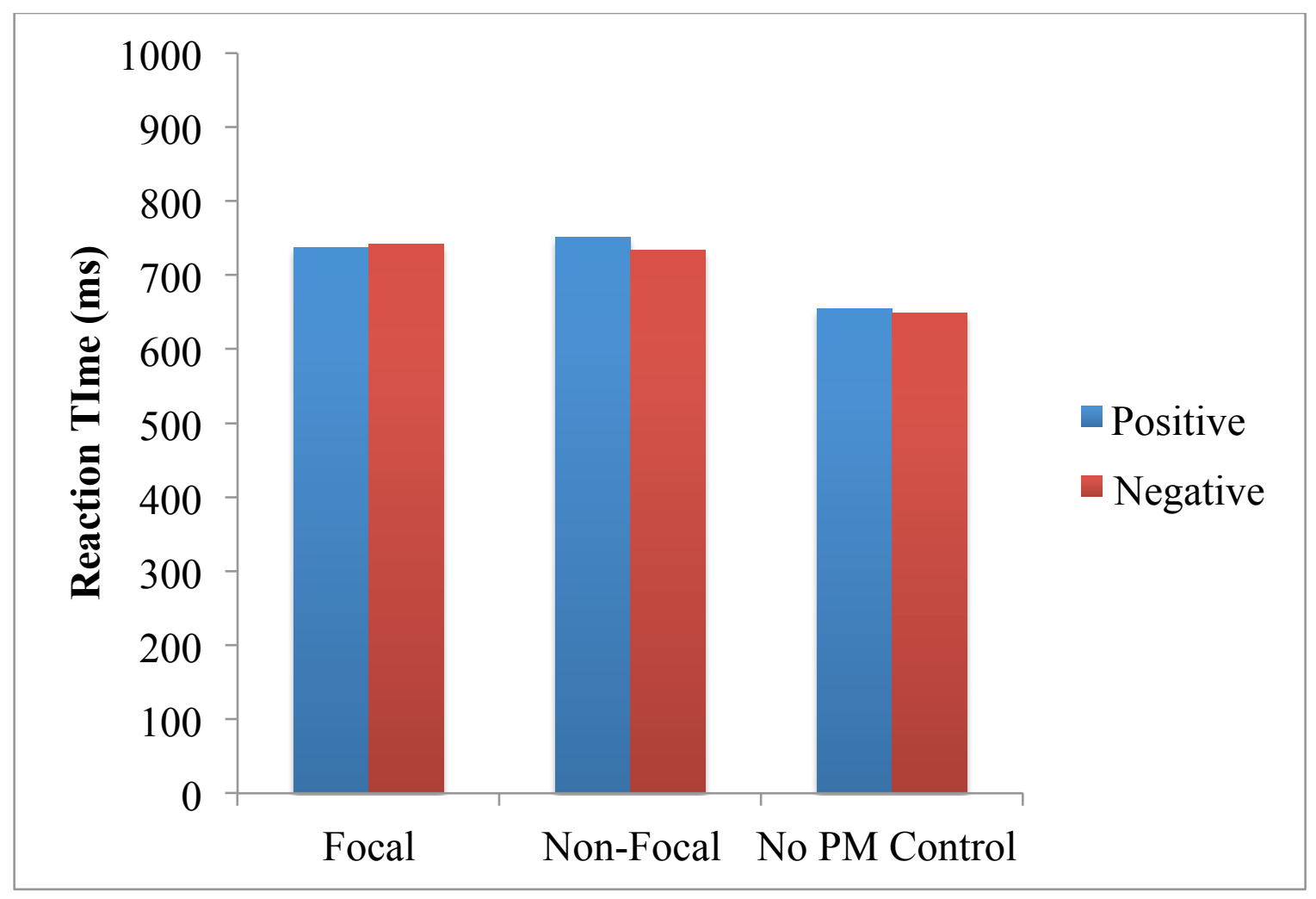

Figure 4. Ongoing task RTs during test block. A main effect of task type was found, such that the control condition completed the ongoing task more quickly than the focal or non-focal conditions.

\section{Mood Non-Responders}

To investigate the possibility that some participants may not respond to a mood induction, mood responders were omitted from the data set for further analysis. For each mood group, their first baseline BMIS score was compared to the second BMIS score, which was collected after the mood induction. If a participant in the negative condition scored above the mean for the negative baseline score $(M=5.015)$, they were omitted. Similarly, any participant in the positive condition who scored lower than the positive baseline score $(M=4.89)$ was also 
omitted. A total of 44 participants were indicated as being a non-responder $(24.3 \%$ of the total sample).

All significant task type main effects reported above were still significant after omitting mood non-responders. In addition, no mood effects were found during this analysis that omitted mood non-responders.

\section{Correlational Analyses}

To further explore possible relationships between dependent measures in each condition, correlational analyses were conducted. Correlations, separated by mood induction and task type, were conducted for the ongoing task reaction times, ongoing task accuracy, and PM task accuracy. Each significant correlation is presented here according to mood (positive, negative) and task type (focal, non-focal, no PM control) conditions.

When a positive mood was induced and a focal task was given, a significant positive correlation was found between the accuracy of the ongoing task and the reaction times of the ongoing task $(r=.44, p=.02)$. When the accuracy of the ongoing task was high, reaction times were also high. No other correlations for this condition were significant. See Table 1 for a summary of this analysis. 
Table 1

Correlational Analysis for the Positive-Focal Condition

\begin{tabular}{lccc}
\hline & $\begin{array}{c}\text { Ongoing Task } \\
\text { Reaction Times }\end{array}$ & $\begin{array}{c}\text { PM } \\
\text { Accuracy }\end{array}$ & $\begin{array}{c}\text { Ongoing Task } \\
\text { Accuracy }\end{array}$ \\
\hline Ongoing Task Reaction Time & & .20 & $.44^{*}$ \\
PM Accuracy & & -.10 \\
Ongoing Task Accuracy & & & \\
\hline$* p<.05$ & & &
\end{tabular}

When a positive mood was induced and a non-focal task was given, a significant positive correlation was found for the PM task accuracy and ongoing task reaction times $(r=.55, p=$ .001). In other words, when the PM task was completed accurately, reaction times for ongoing trials were also high, showing a speed cost to the ongoing task when the PM task was remembered. See Table 2 for a summary of this analysis.

Table 2

Correlational Analysis for the Positive-Non-Focal Condition

\begin{tabular}{lccc}
\hline & $\begin{array}{c}\text { Ongoing Task } \\
\text { Reaction Times }\end{array}$ & $\begin{array}{c}\text { PM } \\
\text { Accuracy }\end{array}$ & $\begin{array}{c}\text { Ongoing Task } \\
\text { Accuracy }\end{array}$ \\
\hline Ongoing Task Reaction Time & & $.55^{* *}$ & .34 \\
PM Accuracy & & .33 \\
Ongoing Task Accuracy & & \\
$* * p<.01$ & &
\end{tabular}


When a negative mood was induced and a focal task was given, no significant correlations were found (all $p$ 's $>.05$ ).

When a negative mood was induced and a non-focal task was given, a significant positive correlation was found between the ongoing task accuracy and PM accuracy $(r=.50, p=.005)$. When the accuracy for the ongoing task was high, the accuracy for the PM task was also high. This could indicate that participants assigned to this condition were overall more accurate in task completion. See Table 3 for a summary of this analysis.

Table 3

Correlational Analysis for the Negative-Non-Focal Condition

\begin{tabular}{lccc}
\hline & $\begin{array}{c}\text { Ongoing Task } \\
\text { Reaction Times }\end{array}$ & $\begin{array}{c}\text { PM } \\
\text { Accuracy }\end{array}$ & $\begin{array}{c}\text { Ongoing Task } \\
\text { Accuracy }\end{array}$ \\
\hline Ongoing Task Reaction Time & .35 & .25 \\
PM Accuracy & & $.50 * *$ \\
Ongoing Task Accuracy & & & \\
$* * p<.01$ & &
\end{tabular}

When investigating positive or negative moods and their effects on the ongoing task without a PM task, no significant correlations were found between ongoing task accuracy and ongoing task reaction times (Positive: $r=.26, p=.18$, Negative: $r=.33, p=.07$ ). A marginally significant effect was found in the negative condition, such that when ongoing task accuracy was high, reaction times were slow. 


\section{PM Cue Monitoring}

To investigate monitoring patterns before each PM cue, reaction times and accuracy for the ongoing task were analyzed for 25 trials before each PM cue was presented. This allowed for a direct test of monitoring patterns at the time PM cues were presented in the task.

\section{Reaction Times}

First, a $3($ PM Cues $) \times 2($ Mood $) \times 3$ (Task Type: Focal, Non-focal, No PM control) ANCOVA was used to compare reaction times across conditions with baseline ongoing reaction time measures as a covariate. No three-way interaction effect was found, $F(4,348)=.77, p=$ .54 , but a significant two-way interaction was found between the PM cue and the task type, $F(4$, $348)=2.46, p=.045$. For a focal task, the first cue showed the most cost $(M=793.62, S D=$ 40.04), followed by the second cue $(M=781.87, S D=30.28)$, with the final cue showing the fastest reaction times $(M=764.00, S D=41.32)$. The difference between cue 1 and cue 3 was marginally significant $(p=.095)$. No other pairwise comparisons for the focal task were significant (all $p$ 's $>.38)$. For a non-focal task, the second cue showed the most $\operatorname{cost}(M=$ $759.42, S D=29.80)$, followed by the first cue $(M=734.15, S D=39.41)$, with the final cue showing the fastest reaction times $(M=702.66, S D=40.67)$. The difference between cue 2 and cue 3 was significant $(p=.005)$ and a marginally significant difference was found between cue 1 and cue $3(p=.07)$. No simple effects were significant for the no PM control condition. In addition, no other two-way interactions were significant (all $p$ 's $>.37$ ). See Figure 5 for a summary of these patterns. 


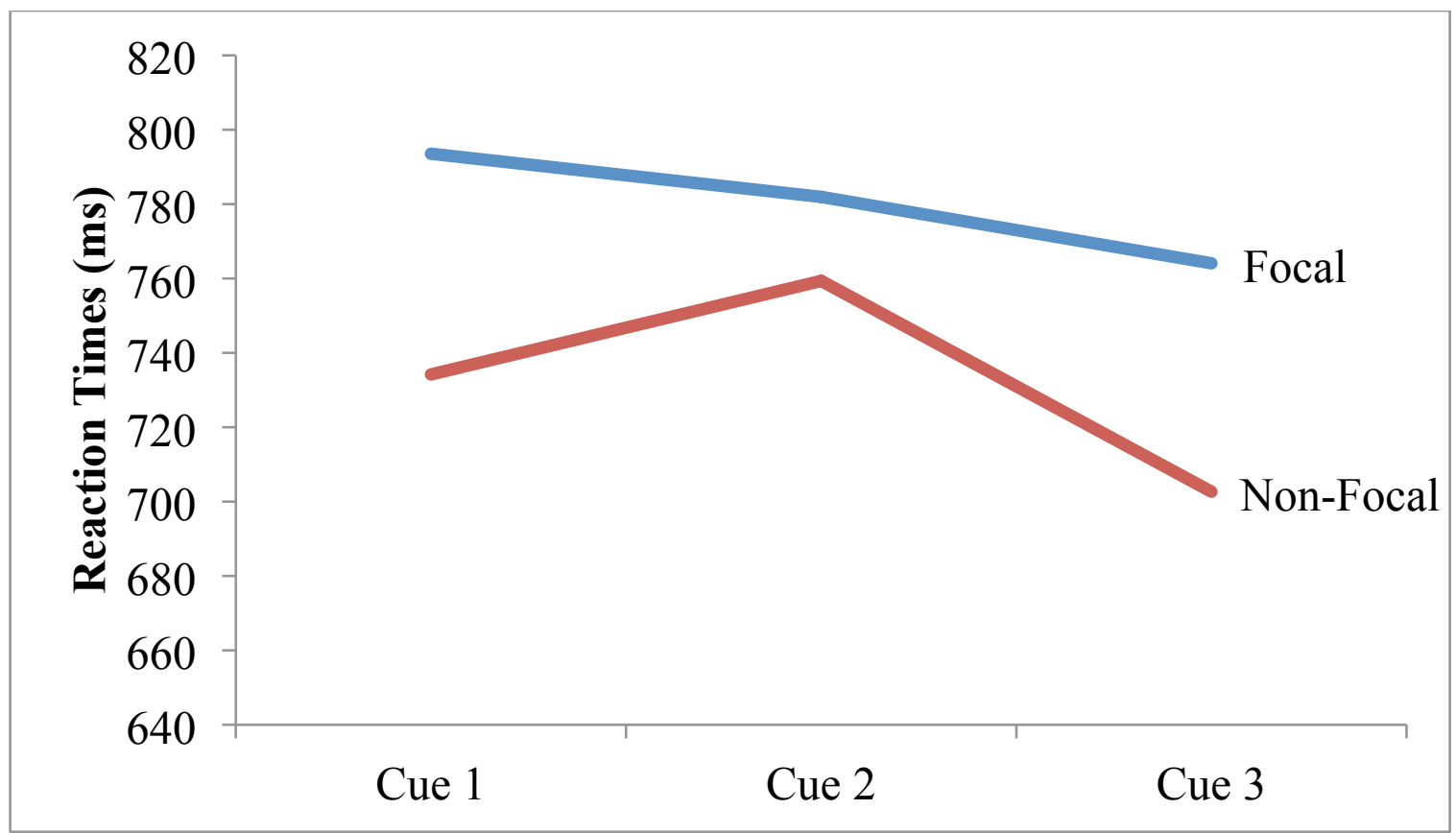

Figure 5. Reaction time cost patterns for each cue by task type. It is shown here that monitoring decreases over time for the focal task. However, for the non-focal task, the first cue and third cue show less cost than the second cue.

An additional ANCOVA was then conducted to investigate mood (Positive, Negative) and task type (Focal, Non-focal, No PM control) effects on the 25 trials before the first PM cue only using baseline ongoing reaction time as the covariate. No main effects or interactions were found, all $p ’ s>.24$.

\section{Accuracy}

A 3 (PM Cues) X 2 (Mood) X 3 (Task Type: Focal, Non-focal, No PM control) ANCOVA was also used to compare using accuracy for the ongoing task across conditions with baseline ongoing accuracy as the covariate. No three-way interaction effect was found, $F(4,346)$ $=.36, p=.84$. A main effect was found for PM cue, $F(2,272)=7.55, p=.001$. Significant 
differences were found between cue $1(M=.97, S D=.07)$ and cue $2(M=.95, S D=.03), p<$ .001 , and cue 2 and cue $3(M=.98, S D=.05), p<.001$. There was no significant difference between cue 1 and cue $3, p=.34$. No significant two-way interaction was found between the PM cue and the mood, $F(1,179)=.21, p=.65$.

An additional ANCOVA was then conducted to investigate effects of mood (Positive, Negative) and task type (Focal, Non-focal, No PM control) on ongoing accuracy for the 25 trials before the first cue only using baseline ongoing accuracy as the covariate. No main effects or interactions were found for this analysis, all $p$ 's $>.19$. 


\section{CHAPTER IV: GENERAL DISCUSSION}

The current study examined the effect of mood at retrieval on PM accuracy and cost to the ongoing task based on the focality of the PM task. I expected to replicate the patterns observed by both Knight et al. (2015) and Rummel et al. (2012) for focal and non-focal tasks, respectively. Recall that Knight et al. (2015) found a decrement for the negative mood condition relative to the positive mood condition in a focal task and Rummel et al. (2012) found a benefit for the negative mood condition relative to the positive mood condition in a non-focal task. Their results are consistent with the MP view and the mood-as-information hypothesis, such that a relational processing style primed by a positive mood should be beneficial when a focal PM task is being completed. However, an item-specific processing style primed by a negative mood is expected to be more beneficial in non-focal tasks that rely more on monitoring for successful task completion.

Specifically, I hypothesized that in the focal condition, participants with a positive mood induction should be more accurate on the PM task than those in a negative mood. This is because a positive mood is thought to elicit a relational processing style, which should aid spontaneous retrieval when the PM task is focal due to the overlap in features processed in the ongoing task relevant to the PM task. I also hypothesized that in the non-focal condition, participants who are given a negative mood induction should perform better on the PM task than those with a positive mood induction. This is because a negative mood should elicit more item-specific processing style, which should aid in active monitoring for the specific PM cues. In a non-focal task, monitoring has been shown to be crucial for successful completion of the PM task (McDaniel \& Einstein, 2000). Neither of these hypotheses regarding accuracy was supported by the current data. The only effect found for PM accuracy was a main effect of task type, which showed 
higher accuracy for a focal task than a non-focal task. This is an effect that has been replicated many times (e.g., Einstein et al., 2005). Because no other effects were found for PM accuracy, especially regarding mood, it is important to consider that mood-based changes may affect PM differently than RM.

In addition, I predicted that reaction times would also follow a specific pattern. Generally, participants who are given a non-focal task should produce longer reaction times than those who are given a focal task. This is because a non-focal task, by nature, requires more active monitoring (Einstein \& McDaniel, 2005). This active monitoring was shown in the current data by a cost to the ongoing task - recorded here by higher reaction times in the non-focal than the focal condition. This is consistent with what has been found in previous literature (e.g., Einstein et al., 2005). Also, I predicted that those who are induced into a negative mood should perform the ongoing task slower overall than those who were induced into a positive mood. This is because a negative mood encourages more active monitoring in the form of item-specific processing, even if the current task may not call for it. However, the current data do not show this trend. No effects of mood were found here in reaction time analyses (overall or in the 25 trials preceding the PM cue), suggesting that if mood affects PM in this way, it was not shown in this data. Recall that the mood manipulation did yield a significant difference between the baseline measures and the second BMIS check. This suggests that the mood manipulation was effective. In addition, when mood non-responders were removed, this did not change any effects found.

Some patterns consistent with the hypotheses were shown in ongoing task reaction times when investigating correlational analyses. Each mood/task type condition seems to a show unique pattern, each of which is discussed in detail here. First, the positive-focal condition 
showed a pattern that when accuracy of the ongoing task was high, reaction times for the task were also high. This suggests that, for this condition, participants who focused on the ongoing task performed it more slowly and accurately. This is a pattern that is reasonable. If a participant were to complete the ongoing task quickly, it is assumed that there would be some cost to accuracy. In the positive-non-focal condition, however, a pattern was shown that higher PM task accuracy resulted in higher reaction times. This is a similar cost-accuracy tradeoff as shown in other research (Einstein et al., 2005), where participants complete the ongoing task more slowly in order to achieve higher PM accuracy. However, these correlation patterns suggest that participants in a positive condition may focus on different portions of the task when given a focal or non-focal task. These results seem to give some indication that when participants are induced into a positive mood, their focus (on the ongoing or the PM task) seems to depend on the type of PM task they are given. In a focal task, participants seem to focus more on the ongoing task. In a non-focal task, participants seem to focus more on the PM task. This is consistent with the MP view suggestion that participants monitor more for PM cues in a non-focal task than a focal task seen is many past studies with the assumption that a positive mood is the more typical/default case for study participants when a specific mood is not induced.

When participants are induced into a negative mood, different patterns are shown. In fact, no significant correlations were found for participants who were given a focal task and a negative mood induction. However, when given a non-focal task, it was shown that higher PM accuracy also predicted high ongoing task accuracy. This could be because, when induced into a negative mood, an item-specific processing style is more likely to occur. When paired with a non-focal task, where monitoring is important, this may cause participants given a negative induction to be more careful about their responses overall in both tasks. This would explain why 
high accuracy in one portion of the task predicts a high accuracy in another. This is difficult to state, however, because if this were true, we should see higher reaction times for this condition. Another possibility is that the participants assigned to this condition were just more conscientious in task completion overall. Further explanations should be explored to determine how mood affects this task type.

The current study showed several additional patterns that should be discussed. First, PM accuracy overall was rather low, with only about $55 \%$ of the total cues detected when a PM task was given (the range for each condition was $0-100 \%$ cue detection). As a comparison, Knight et al. (2015) reported mean accuracies for their neutral condition of their first experiment above $70 \%$ (The authors did not report actual means). This low performance could be caused by several factors, such as a lack of motivation to complete the task or a focus on another portion of the experiment— such as the ongoing task. In addition, it may also be possible that this lower performance could be due to the timing of the mood induction. Knight et al. (2015) induced their participants at PM task encoding, whereas I induced my participants at PM task retrieval. This may indicate that mood effects may be stronger at encoding than at retrieval. A recent study by Workman and McBride (In Preparation, 2017) provided support for this idea. In this study, the researchers induced matching or mismatching moods at encoding and at retrieval. They found that mood did have an impact on the ongoing task accuracy. This suggests that there may be stronger mood effects on PM when induced at encoding rather than at retrieval. It is important to investigate all of these possibilities to truly understand how PM tasks are being processed in different affective states. Further research should consider motivation of the participants to complete the tasks, if possible. This will determine if this low accuracy could be due to a lack of motivation or another external variable — such as the timing of the mood induction. 
In addition to low accuracy, a fairly large portion of the sample (24.3\%) was indicated as a mood non-responder. This is high in comparison to previous studies, such as Rummel et al.'s (2012), where only $8 \%$ of their sample were reported as being non-responders. The high number of mood non-responders in the current study could be due to a lack of motivation for the induction. It is also possible that the high number of non-responders could be due to our particular sample. For example, our sample could be less motivated to complete the task than samples in previous studies. Another possibility is that our sample was particularly unresponsive to the mood induction. Regardless, it is important to take into consideration that, for a large portion of the sample, the mood manipulation was not successful. The correlational analyses reported for the current study seem to give some indication that mood effects are still present. However, because these are correlational, causation cannot be determined. Future research should consider either a stronger mood induction procedure or perhaps a more motivational design. This will hopefully show more clear effects of how mood affects PM.

The current study did not affirm the hypotheses. However, the focal/non-focal overall comparisons did affirm the nature of PM retrieval as posited by the MP view, rather than the PAM view. The current research also gives us more knowledge on the processes that are occurring in event-based PM tasks. Even though no mood effects were found, the patterns reported in the current study lead to clues that may be important in future research. Further research is needed to continue the examination of mood effects in event-based PM. Although the current study showed no direct mood effects, it did give us some insight on what might actually be happening in real-world PM tasks. For example, it was shown here that effects may not be as strong, or even present, when moods are induced before retrieval. Moods at encoding may have a stronger effect as shown in the Rummel et al. (2012) and Knight et al. 
(2005) studies. Future research may allow us to produce more helpful suggestions for remembering to complete PM tasks outside of the lab. For example, future research may help us understand the likelihood of someone remembering to take his or her medicine if that individual has depression. Or, perhaps, if someone has an upcoming doctor appointment that they are dreading, how likely is it they will remember the appointment? These are important questions, which, if researched further, may benefit individuals who suffer from mood-based ailments or even an average person who just has a bad day. 


\section{REFERENCES}

Balota, D., Yap, M., Cortese, M., Hutchison, K., Kessler, B., Loftis, B., Neely, J., Nelson, D., Simpson, G., \& Treiman, R. (2007). The english lexicon project. Behavior Research Methods, 39, 445-459.

Bradley, M., \& Lang, P. (1999). Fearfulness and affective evaluations of pictures. Motivation and Emotion, 23, 1-13.

Brewer, G., Knight, J., Marsh, R., \& Unsworth, N. (2010). Individual differences in event-based prospective memory: Evidence for multiple processes supporting cue detection. Memory \& Cognition, 38, 304-311. doi:10.3758/MC.38.3.304

Cuttler, C., Relkov, T., \& Taylor, S. (2014). Quick to act, quick to forget: The link between impulsiveness and prospective memory. European Journal of Personality, 28, 560-568.

Eich, E. (1995). Mood as a mediator of place dependent memory. Journal of Experimental Psychology: General, 124, 293-308. doi:10.1037/0096-3445.124.3.293

Eich, E., \& Metcalfe, J. (1989). Mood-dependent memory for internal versus external events. Journal of Experimental Psychology: Learning, Memory, and Cognition, 15, 443-455.

Einstein, G., Holland, L., McDaniel, M., \& Guynn, M. (1992). Age-related deficits in prospective memory: The influence of task complexity. Psychology and Aging, 7, 471478. doi:10.1037/0882-7974.7.3.471

Einstein, G., \& McDaniel, M. (1990) Normal aging and prospective memory. Journal of Experimental Psychology: Learning, Memory, and Cognition, 16, 717-726.

Einstein, G., \& McDaniel, M. (2005). Prospective memory: Multiple retrieval processes. Current Directions in Psychological Science, 14, 286-290. doi:10.1111/j.09637214.2005.00382.x 
Einstein, G., McDaniel, M., Thomas, R., Mayfield, S., Shank, H., Morrisette, N., \& Breneiser, J. (2005). Multiple processes in prospective memory retrieval: Factors determining monitoring versus spontaneous retrieval. Journal of Experimental Psychology: General, 134, 327-342. doi:10.1037/0096-3445.134.3.327

Faul, F., Erdfelder, E., Lang, A. G., \& Buchner, A. (2007). G*Power 3: A flexible statistical power analysis program for the social, behavioral, and biomedical sciences. Behavior Research Methods, 39, 175-191.

Fiedler, K. (2001). Affective states trigger processes of assimilation and accommodation. In L.L. martin \& G.L. Clore (Eds.) Theories of mood and cognition: A user's guidebook (86-98). Mahwah, NJ: Erlbaum.

Gasper, K., \& Clore, G.L. (2002). Attending to the big picture: Mood and global versus local processing of visual information. Psychological Science, 13, 34-40.

Hunt, R. \& McDaniel, M. (1993). The enigma of organization and distinctiveness. Journal of Memory and Language, 32, 421-445.

Kliegel, M., Jäger, T., Phillips, L., Federspiel, E., Imfeld, A., Keller, M., \& Zimprich, D. (2005). Effects of sad mood on time-based prospective memory. Cognition and Emotion, 19, 1199 -1213. doi:10.1080/02699930500233820

Knight, J., Brewer, G., Ball, B., DeWitt, \& Marsh, R. (2015). The influence of mood on the process and content of encoding future intentions. The Quarterly Journal of Experimental Psychology, 68, 1082-1100. doi:10.1080/17470218.2014.975729

Marsh, R., Cook, G., \& Hicks, J. (2006) An analysis of prospective memory. In D. L. Medin (Ed.), The psychology of learning and motivation, 46, 115-153. San Diego, CA: Academic Press. 
Marsh, R., Hicks, J., Cook, G., Hansen, J., \& Pallos, A. (2003). Interference to ongoing activities covaries with the characteristics of an event-based intention. Journal of Experimental Psychology: Learning, Memory, and Cognition, 29, 861-870.

Mayer, J., \& Gasschke, Y. (1988). The experience and meta-experience of mood. Journal of Personality and Social Psychology, 55, 102-111.

McBride, D. M., \& Workman, R. A. (in press). Is prospective memory unique? A comparison of prospective and retrospective memory. In B. Ross (Ed.), Psychology of Learning and Motivation, vol. 67. San Diego, CA: Academic Press/Elsevier.

McDaniel, M., \& Einstein, G. (2000). Strategic and automatic processes in prospective memory retrieval: A multiprocess framework. Applied Cognitive Psychology, 14, S127-S144. doi:10.1002/acp.775

McDaniel, M., \& Einstein, G. (2007) Prospective memory: An overview and synthesis of an emerging field. Thousand Oaks, CA.: Sage Publications.

Rummel, J., Hepp, J., Klein, S. A., \& Silberleitner, N. (2012). Affective state and event-based prospective memory. Cognition and Emotion, 26, 351-361. doi: $10.1080 / 02699931.2011 .574873$

Schnitzspahn, K., Stahl, C., Zeintl, M., Kaller, C., \& Kliegel, M. (2013). The role of shifting, updating, and inhibition in prospective memory performance in young and older adults. Developmental Psychology, 49, 1544.

Schnitzspahn, K., Thorley, C., Phillips, L., Voigt, B., Threadgold, E., Hammond, E., \& Kliegel, M. (2014). Mood impairs time-based prospective memory in young but not older adults: The mediating role of attentional control. Psychology and Aging, 29, 264-270. doi:10.1037/a0036389 
Scullin, M., McDaniel, M., \& Shelton, J. (2013). The dynamic multiprocess framework: Evidence from prospective memory with contextual variability. Cognitive Psychology, 67, 55-71. doi:10.1016/j.cogpsych.2013.07.001

Smith, R. (2003). The cost of remembering to remember in event-based prospective memory: Investigating the capacity demands of delayed intention performance. Journal of Experimental Psychology: Learning, Memory, and Cognition, 29, 347-361. doi: $10.1037 / 0278-7393.29 .3 .347$

Storbeck, J., \& Clore, G. L. (2005). With sadness comes accuracy; With happiness, false memory: Mood and the false memory effect. Psychological Science, 16, 785-791. doi:10.1111/j.1467-9280.2005.01615.x

Storbeck, J., \& Clore, G. L. (2011). Affect influences false memories at encoding: Evidence from recognition data. Emotion, 11, 981-989. doi:10.1037/a0022754

Thorley, C., Dewhurst, S. A., Abel, J. W., \& Knott, L. M. (2016). Eyewitness memory: The impact of a negative mood during encoding and/or retrieval upon recall of a non-emotive event. Memory, 24, 838-852. doi:10.1080/09658211.2015.1058955

Velten, E. (1968) A laboratory task for the induction of mood. Behaviour Research and Therapy, $6,473-482$.

Workman, R. A, \& McBride, D. M. (In Preparation, 2017) The effect of mood on event-based prospective memory. 